\title{
DESIGN METHOD FOR LIGHT-GAUGE STEEL SHEAR WALLS SHEATHED WITH FLAT STEEL PLATES
}

\author{
L.A. Fülöp ${ }^{1, *}$ and I. Hakola \\ ${ }^{I} V T T$ - Technical Research Centre of Finland \\ P.O. Box 1000, FI-02044 VTT \\ Tel. +35820722 111; Fax +358207227001 \\ *(Corresponding author: E-mail: Ludovic.Fulop@vtt.fi ; Ilkka.Hakola@vtt.fi) \\ Received: 8 January 2007; Revised: 19 March 2007; Accepted: 28 March 2007
}

\begin{abstract}
Sheathed Light-Gauge Steel (LGS) shear walls are often used in structures as load bearing elements against wind and earthquake actions. The design of walls is often complicated by the lack of analytical methods for the evaluation of the strength and rigidity. Design by testing is a possibility if large numbers of identical walls are used; but in the usual case designers are limited by economic consideration to use configurations which were already tested. These limitations greatly reduce the potential of using LGS shear walls in practical applications. In this paper an analytical design procedure is presented for LGS shear walls sheathed with flat thin steel plates. The procedure, developed for the evaluation of the shear strength and rigidity of the walls, takes into account the fixing of the steel plate to the skeleton. The method is validated using both Finite Element Modelling (FEM) and experiments; comparisons show good accuracy when it comes to the evaluation of strength, but not satisfactory for the rigidity.
\end{abstract}

Keywords: Light-gauge steel, shear walls, lateral loading, design method, tension-field action

\section{INTRODUCTION}

In LGS structures the wall sheathing often contributes to the load bearing of the system. One of the sheathing solutions, used for such walls, is based on flat steel in which cases a thin steel sheath $(\mathrm{t}=0.6-1.2 \mathrm{~mm})$ is attached to one or both sides of the skeleton of the wall. The method can be used both in multi-storey applications and single family houses (Figure 1).

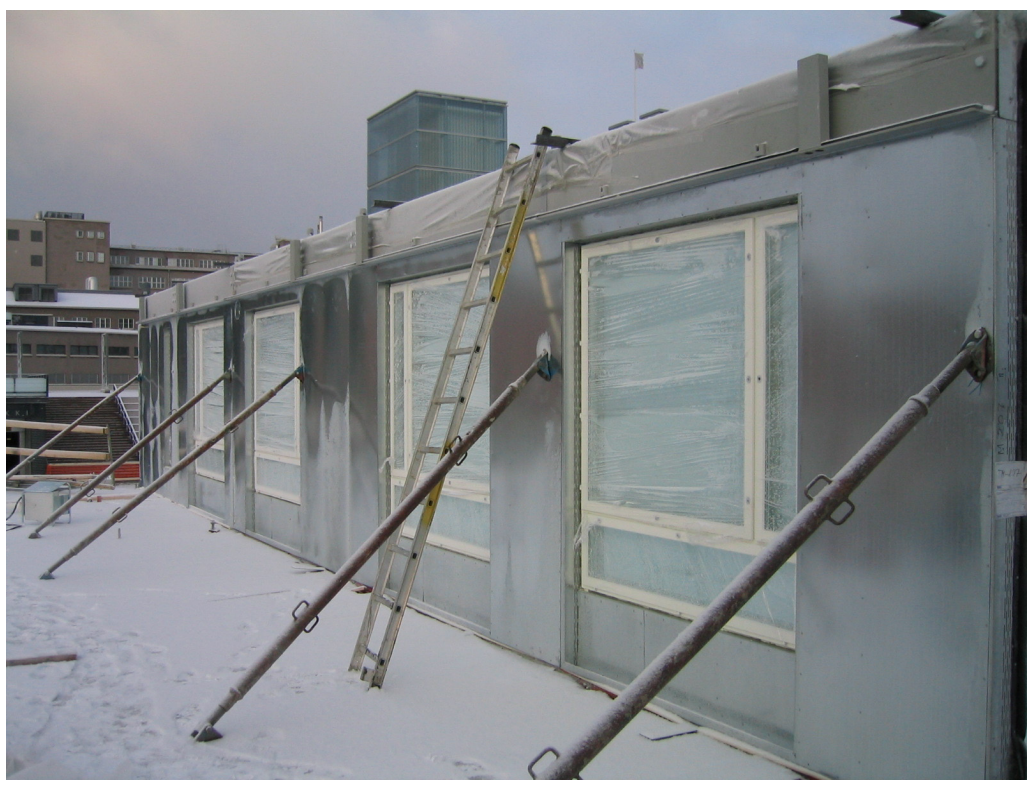

Figure 1. NORDICON Wall Elements with Flat Steel Sheath (As Oy - Arabian Kotiranta; Builder: Sato Rakennuttajat Oy; Architect: Ark Oy Kahri \& Co.; Wall: Ruukki) 
One of the particularly interesting applications, in housing, is the use of thin steel cassette sections, Davies [1]. Even if the cassette walls are slightly different from the classical sheathed solutions, the load bearing mechanism is similar. In the case of cassette walls, the connected flanges of the cassettes form the "stud", while the large webs act as the sheathing (Figure 2).

a)

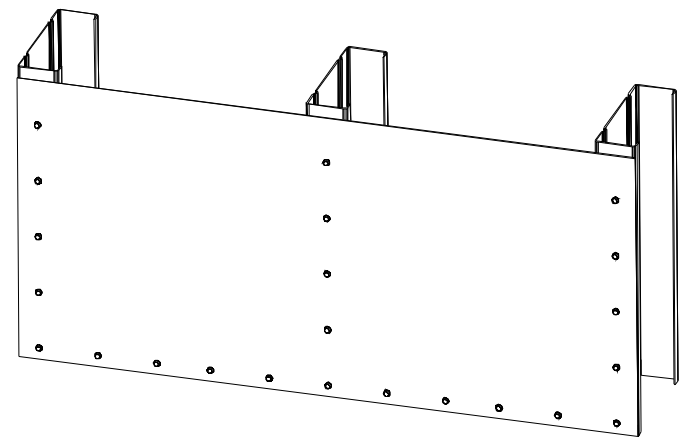

b)

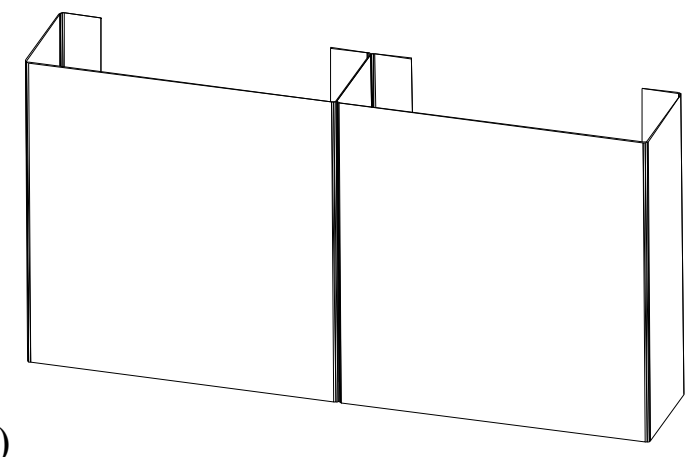

Figure 2. (a) Steel Skeleton Walls with Flat Steel Sheathing and (b) Cassette Section Walls

Obviously, the sheathing provides a certain amount of stiffening for the wall, especially if the wall is loaded in shear. Such loading typically occurs in the wall when the structure is subjected to wind or earthquake action. In order to design a structure for these actions, the evaluation of the lateral load bearing capacity is required, with a significant part of the strength supplied by the sheathing. The main limitation in the design process comes from the lack of suitable analytical procedures for the calculation of the capacity and rigidity of the sheathed walls. Design assisted by testing is one possibility, but it is usually expensive and impractical, due to the diversity of configurations and dimensions of walls in everyday design.

In this paper an analytical design procedure is presented for the evaluation of the strength and rigidity of shear walls sheathed with flat steel plates. The procedure takes into account the strength and the rigidity of the connections between the plate and the frame of the wall, and proved to be sufficiently accurate for the evaluation of the strength of the walls, but less reliable for the evaluation of the stiffness. Several particularities of the behaviour of LGS shear walls, useful during the design process, are highlighted and critically discussed.

\section{HISTORICAL DEVELOPMENT OF THE STEEL SHEAR WALLS}

To some extent, the calculation methods for classical steel shear walls, used in heavy frame structures, can also be adopted for LGS walls. However, important differences also exist between the two typologies. These differences, and their consequences on the behaviour of the walls, are discussed in this section.

Flat steel plates with larger thickness $(t \approx 5-10 \mathrm{~mm})$ are sometimes provided in bays of multi-storey steel frame structures in order to improve the earthquake performance. These shear plates increase the lateral rigidity and load bearing capacity of the structure, and also contribute to the energy dissipation during earthquake. [2].

Initially, in these classical applications, the intention was to avoid the elastic buckling of the plates. Until the 1980s, the design limit-state of steel plate shear walls, in North-America, was the out-of-plane buckling of the plate, resulting in the use of very robust walls [3]. Unquestionably, elastic buckling offers inferior performance as compared to plastic failure of the steel plate, especially in terms of dissipative capacity. 
Plastic yielding of the plate was facilitated in practical applications by providing out-of-plane stiffeners. Besides the out-of-plane stiffeners, two other solutions were proposed with the aim of facilitating plastic failure instead of elastic buckling. The use of low-yield steel, as base material for the plates, was introduced in Japan [4]; and pure aluminium shear walls were proposed by DeMatteis [5]. In both cases the goal is to exploit the low yield capacity of the material in order to facilitate shear yielding.

Stiffened shear walls were used in most of the early applications in Japan and the USA [6], but this method became less popular as it requires large amount of labour for the welding of the stiffeners. An increasing number of recent applications, both in the USA and Canada, use non-stiffened steel plates [6]. In case of non-stiffened walls, elastic buckling is allowed to take place, and the load resisting mechanism is based on the development of tensile stresses in the already buckled plate, mechanism often referred as tension-field action.

The first tension-field theory concerning the post-buckling strength of shear panels was developed by Wagner [7]. Later theories incorporated the bending effect of the marginal beams and shear stresses in the plate [8]. A plastic design method for the classical steel shear walls was presented, for single-storey and multi-story frames, by Berman \& Bruneau [3].

More recently, Elgaaly [2] proposed an analytical model for the calculation of the capacity of shear walls with both welded and bolted thin steel plates. The model is based on the concept of replacing the sheathing with a series of equivalent trusses. For the case of bolted steel plates Elgaaly [2] suggested, that the shear wall should be designed so that the yielding of the plate, and not the capacity of the end connections, should control the failure of the shear wall. It will be shown later in this paper, that this condition can hardly, if at all, be fulfilled with LGS shear walls.

In the case of LGS walls, it is also not possible to avoid the elastic buckling, due to the extreme thinness of the plate. If we would include LGS shear plates in the slenderness chart presented by Astaneh-Asl [6], they would form a group of "extremely slender" plates with very large width-to-thickness ratios $(L / t \approx 600-1200$, Figure 3$)$. Therefore, the use of stiffeners or low-yield material is not feasible, and the storey shear has to be transmitted by the tension-field action only.

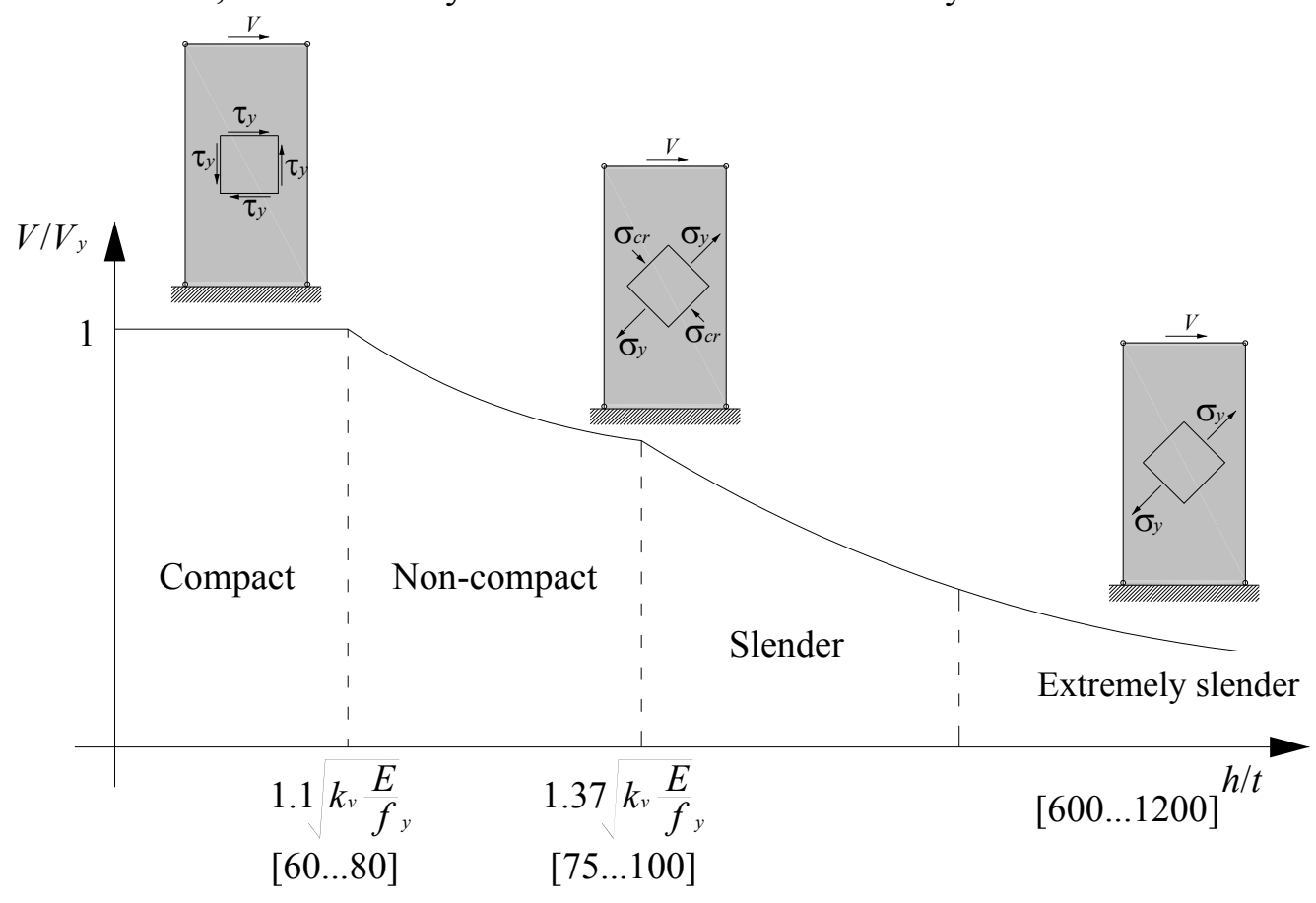

Figure 3. Behaviour of Steel Shear Walls (Adapted from Astaneh-Asl [6]) 
The other difference between classical and LGS walls, is that in the heavy steel applications the plates are usually continuously connected to the frame, most often by welding. But welding is rarely used in LGS structures, because of the damage it causes to the zinc coating of the elements, and the connection of the plate is usually in points, by screws or pins.

\section{CALCULATION METHOD FOR WALLS WITH STEEL PLATES CONTINUOUSLY CONNECTED TO THE FRAME}

\subsection{Basic Assumptions}

The calculation of shear walls, covered by thin steel sheathing, is based on the assumption that the shear is resisted by the tension-field action in the plate (Figure 3). Other assumptions include:

(i) The skeleton of the wall is pinned. This implies that the connections between studs and tracks do not transmit bending, and the frame effect of the wall skeleton is negligible.

(ii) The bending rigidity of studs and tracks is large, as compared to the rigidity of the thin plate. Therefore, the studs and tracks do not bend significantly during the deformation of the wall. This assumption may be doubtful when it comes to relatively long studs.

In the first step of the analysis, the wall panel is divided along the length into cells, which are sheathed with a single steel plate (Figure 4). If the cells are identical, they act in parallel and the shear loading of the wall is transmitted equally to each cell. Since the capacity and rigidity of the cells can be summed, the calculation method for these values has been developed for one cell.

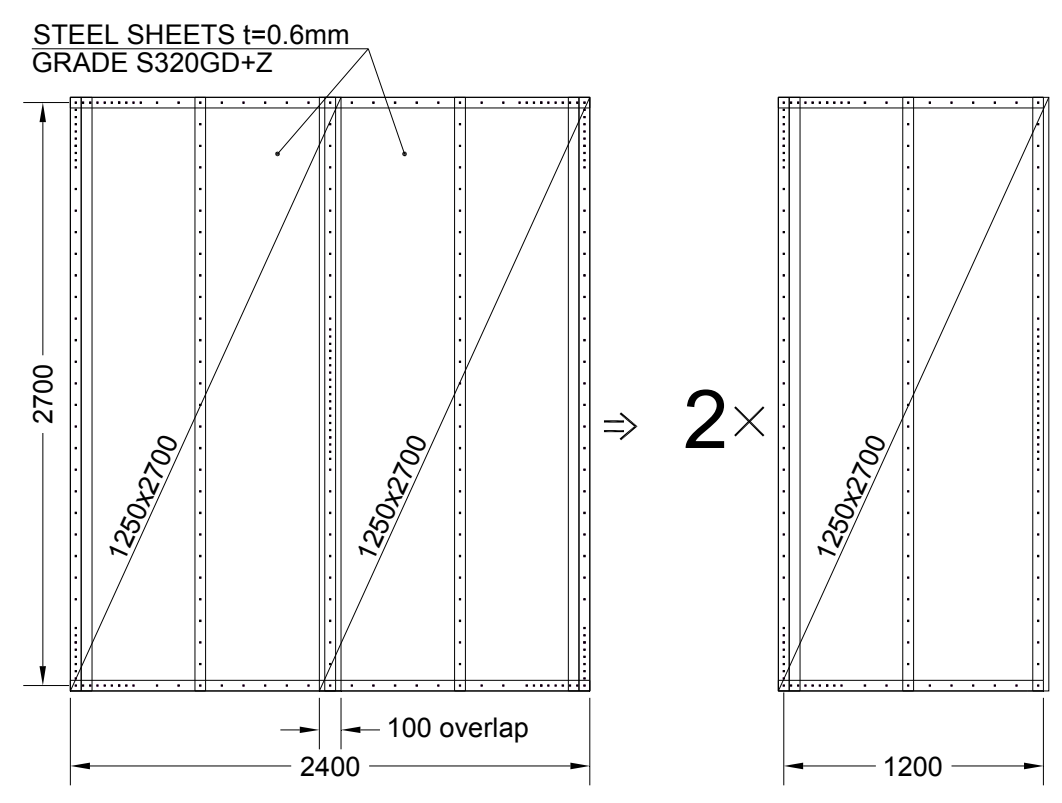

Figure 4. Division of Wall Panels into "Cells"

Buckling of the plate occurs in the very early stage, and at small forces, due to the very large width-to-thickness ratios (L/t $\approx 600-1200)$. However, the buckling force does not represent the ultimate capacity of the wall, because the post-buckling path is stable, and the load can substantially increase due to tension-field action. An oblique tension stress pattern develops in the plate resembling a pattern of oblique strips subjected to tension (Figure 5.a). These strips yield gradually, leading to the loss of load bearing capacity of the cell, and of the entire wall. 
For analytical purposes, the cells can be divided into finite strips running obliquely and forming an angle $\alpha$ with the vertical. The position of the current strip is defined by its distance from the corner of the cell (x), while its width is $d x$ (Figure 5.a). The load bearing capacity of the cell is calculated by supposing that the only mechanism to resist the loading is the strips subjected to stretching.

As presented in Figure 5.a, the strips can have different characteristics (e.g. length, axial stiffness), depending on their position in the plate. Based on the geometry, several zones of strips can be defined. As shown later, the behaviour of strips in the same zone can be described by identical formulae. In the elastic stage, the structural scheme of this multi-strip model is staticallyindeterminate, but when all strips yielded classical plastic analysis apply. In the yielding stage the forces in every strip are known, and equal to the yield resistance of the strip.

Finite Element (FE) analyses and experimental evidence suggest that independent yield patterns develop for each cell of a wall, thus substantiating the assumption that the cells in a wall act independently.

(a)

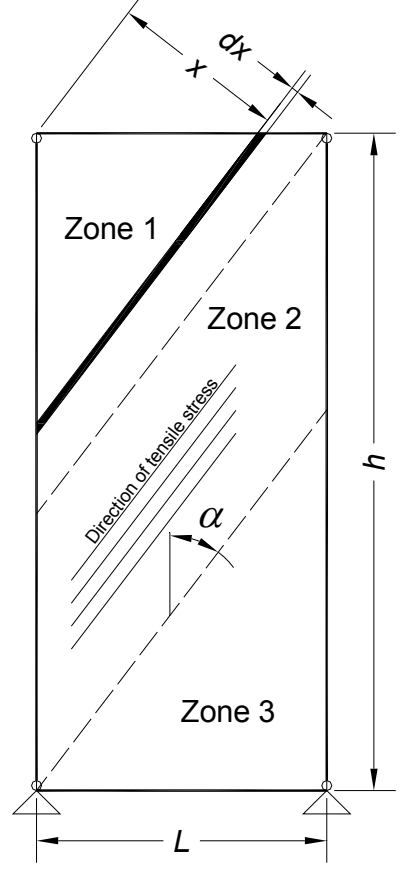

(b)

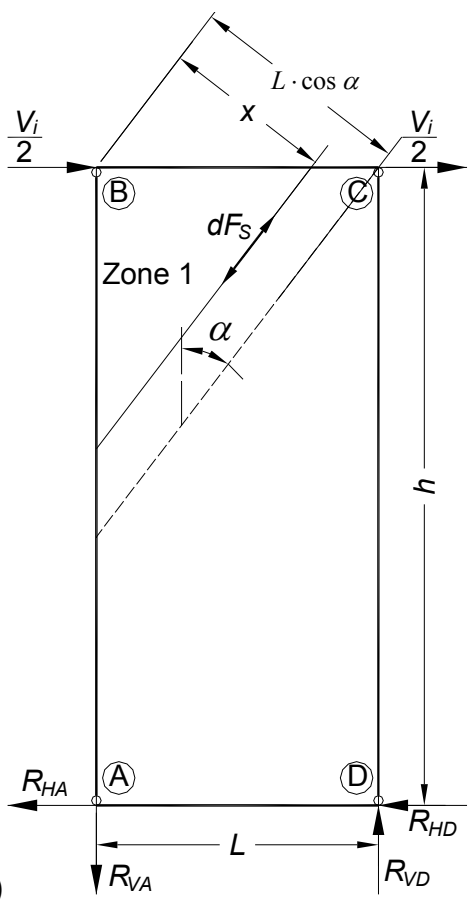

Figure 5. (a) Differential strips $(d x)$ and Zones, (b) forces in strips from horizontal loads $\left(V_{i}\right)$

\subsection{Evaluation of the Load Bearing Capacity}

The relationship between the tensile force in the strip $\left(d F_{s}\right)$ and the horizontal force $\left(V_{i}\right)$ that causes it (Figure 5.b), can be written for strips in Zone 1 as:

$V_{i}=\frac{d F_{S} \cdot x}{h}$

If $d F_{S}$ is interpreted as the resistance of the strip, then $V_{i}$ will represent the contribution of the strip to the capacity of the cell. The total load bearing capacity contribution of strips in Zone $1\left(V_{i}^{\text {Zonel }}\right)$ can be calculated by summing up the contributions of individual strips in the entire Zone 1: 
$V_{i}^{\text {Zone } 1}=\int_{x=0}^{L \cdot \cos \alpha} \frac{d F_{S} \cdot x}{h}$

Similarly the load bearing contributions of all strips in Zone $2\left(V_{i}^{\text {Zone2 }}\right)$ and Zone $3\left(V_{i}^{\text {Zone } 3}\right)$ are:

$$
\begin{aligned}
& V_{i}^{\text {Zone } 2}=\int_{x=L \cdot \cos \alpha}^{h \cdot \sin \alpha} \frac{d F_{S} \cdot L \cdot \cos \alpha}{h} \\
& V_{i}^{\text {Zone } 3}=\int_{x=h \cdot \sin \alpha}^{h \cdot \sin \alpha+L \cdot \cos \alpha} \frac{d F_{S} \cdot[(h \cdot \sin \alpha+L \cdot \cos \alpha)-x]}{h}
\end{aligned}
$$

By simplifying Eq. (4) it can be shown that the contributions of strips in Zone 1 and Zone 3 are equal. Intuitively it can also be seen that the two zones are identical from the point of view of the load bearing. Therefore:

$$
V_{i}^{\text {Zone } 3}=\int_{x=0}^{L \cdot \cos \alpha} \frac{d F_{S} \cdot x}{h}=V_{i}^{\text {Zone } 1}
$$

The total horizontal load bearing capacity of the cell $(V)$, in the stage when all strips yield, is the sum of the contributions of the three zones:

$$
V=V_{i}^{\text {Zone1 }}+V_{i}^{\text {Zone } 2}+V_{i}^{\text {Zone3 }}=2 \cdot V_{i}^{\text {Zone1 }}+V_{i}^{\text {Zone2 }}
$$

As the yield resistance of all strips is equal to $d F_{S}=d A \cdot f_{y}=t \cdot d x \cdot f_{y}$, the total capacity expressed in Eq. 6 can be calculated as:

$$
\begin{aligned}
V & =2 \cdot \int_{x=0}^{L \cdot \cos \alpha} \frac{d F_{S} \cdot x}{h}+\int_{x=L \cdot \cos \alpha}^{h \cdot \sin \alpha} \frac{d F_{S} \cdot L \cdot \cos \alpha}{h}= \\
& =2 \cdot \frac{t \cdot f_{y}}{h} \int_{x=0}^{L \cdot \cos \alpha} x \cdot d x+\frac{t \cdot f_{y} \cdot L \cdot \cos \alpha}{h} \int_{x=L \cdot \cos \alpha}^{h \cdot \sin \alpha} d x=\frac{1}{2} \cdot t \cdot f_{y} \cdot L \cdot \sin (2 \alpha)
\end{aligned}
$$

The background of this expression was presented in more detail by Berman and Bruneau [3] for classical steel shear walls used in multi-storey frames.

\subsection{Evaluation of the Rigidity}

Based on the assumption that the frame is pinned, and made of very rigid bars that do not bend, it can be noticed that the deformed shape of the cell is geometrically determined (Figure 6). This means that the lengthening and the corresponding force in each strip can be calculated for any horizontal displacement of the top. Therefore, the rigidity of the cell can be evaluated.

A deformation $\Delta$ at the top of the cell causes the points 1 and 2 to displace with $\Delta_{1}$ and $\Delta_{2}$ (Figure 6). If the deformations are small, it can be accepted that the two points have only horizontal displacements. 


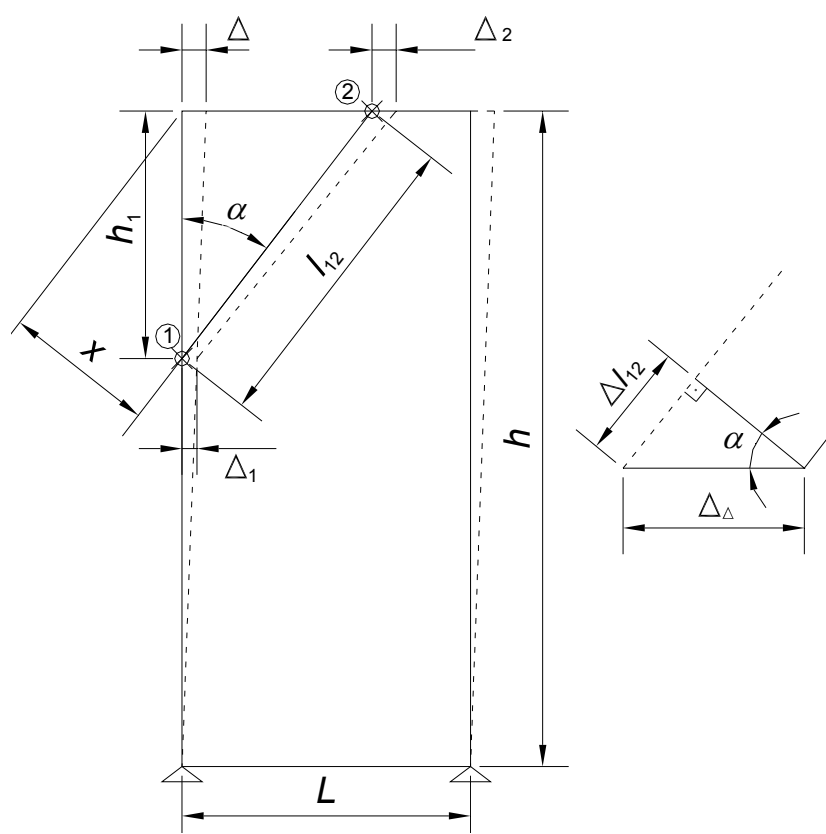

Figure 6. Strip in the Deformed Stage of the Cell (Zone 1)

The length $\left(l_{12, Z 1}\right)$ of a strip in Zone 1, at a distance $x$ from the corner, is:

$$
l_{12, Z 1}=\frac{x}{\sin \alpha \cdot \cos \alpha}
$$

The lengthening of the strip $\left(\Delta l_{12, Z 1}\right)$ corresponding to the top displacement of $\Delta$ can be expressed as:

$$
\Delta l_{12, Z 1}=\frac{\Delta \cdot x}{h}
$$

The deformations $\Delta l_{12, Z 1}$ and $\Delta$ can be expressed as a function of the strip force $\left(d F_{S}\right)$ and the contribution of $d F_{S}$ to the load bearing of the wall $\left(V_{i}\right)$ :

$$
\frac{d F_{S}}{k_{s, Z 1}}=\frac{x}{h} \cdot \frac{V_{i}}{d k_{t}^{Z 1}}
$$

Where $k_{s, Z 1}$ is the axial rigidity of the current strip, and $d k_{t}^{Z 1}$ is the strips contribution to the shear rigidity of the cell.

Also, by using the formula of $V_{i}$ (Eq. 1), the rigidity contribution of one strip in Zone 1 to the horizontal rigidity of the cell $\left(d k_{t}^{Z 1}\right)$ can be written:

$d k_{t}^{Z 1}=\frac{x^{2}}{h^{2}} \cdot k_{s, Z 1}$

Similarly, the length of a strip in Zone $2\left(l_{12, Z 2}\right)$ is:

$$
l_{12, Z 2}=\frac{L}{\sin \alpha}
$$


The elongation of a strip in Zone $2\left(\Delta l_{12, Z 2}\right)$ :

$$
\Delta l_{12, Z 2}=\Delta \cdot \frac{L \cdot \cos \alpha}{h}
$$

And the contribution of a strip in Zone $2\left(d k_{t}^{Z 2}\right)$ to the rigidity of the wall reads:

$$
d k_{t}^{Z 2}=\frac{L^{2} \cdot \cos ^{2} \alpha}{h^{2}} \cdot k_{s, Z 2}
$$

The strips in Zone 3 are similar to the ones in Zone 1, their contribution to the rigidity of the cell being identical to the ones in Zone 1 .

The combined rigidity contribution of the strips in Zone 1 to the rigidity of the wall $\left(K^{\text {Zonel }}\right)$ is the summation of the rigidity contribution of each strip:

$$
K^{Z o n e 1}=\int_{0}^{L \cdot \cos \alpha} d k_{t}^{Z 1}=\int_{0}^{L \cdot \cos \alpha} \frac{x^{2}}{h^{2}} \cdot k_{s, Z 1}=\frac{E \cdot t \cdot L^{2} \cdot \sin \alpha \cdot \cos ^{3} \alpha}{2 \cdot h^{2}}
$$

Where the rigidity of strips in Zone $1\left(k_{s, Z 1}\right)$ is:

$$
k_{s, Z 1}=\left(\frac{E \cdot A}{l_{12, Z 1}}\right)=E \cdot t \cdot d x \cdot \frac{\sin \alpha \cdot \cos \alpha}{x}
$$

Similarly for Zone 2:

$$
\begin{aligned}
& K^{Z \text { one } 2}=\int_{L \cdot \cos \alpha}^{h \cdot \sin \alpha} d k_{t}^{Z 2}=\int_{L \cdot \cos \alpha}^{h \cdot \sin \alpha} \frac{L^{2} \cdot \cos ^{2} \alpha}{h^{2}} \cdot k_{s, Z 2}= \\
& =\frac{E \cdot t \cdot L \cdot \sin \alpha \cdot \cos ^{2} \alpha}{h^{2}} \cdot(h \cdot \sin \alpha-L \cdot \cos \alpha)
\end{aligned}
$$

If the rigidity contributions of the strips in Zones 1, 2 and 3 are summed up, the total rigidity of the cell $\left(K_{T O T}\right)$ is obtained as follows:

$$
K_{\text {TOT }}=2 \cdot K^{\text {Zone } 1}+K^{\text {Zone } 2}=\frac{1}{4} \cdot \frac{E \cdot t \cdot L}{h} \sin ^{2}(2 \cdot \alpha)
$$

\subsection{Characteristics of the Plate Yielding}

If we suppose that the strips behave in an elastic-plastic manner, it can be shown that all strips in the cell yield simultaneously at a lateral displacement of the wall $\Delta_{y}$.

For strips in Zone 1 (and Zone 3) the yield elongation of any strip $\left(\Delta l_{12 y, Z 1}\right)$ is (using Eq. 8):

$$
\Delta l_{12 y, Z 1}=\varepsilon_{y} \cdot l_{12, Z 1}=\frac{f_{y}}{E} \cdot \frac{x}{\sin \alpha \cdot \cos \alpha}
$$


For the strips in Zone 2, $\Delta l_{12 y, Z 1}$ is (from Eq. 12):

$$
\Delta l_{12 y, Z 2}=\varepsilon_{y} \cdot l_{12, Z 2}=\frac{f_{y}}{E} \cdot \frac{L}{\sin \alpha}
$$

Both of these elongations correspond to a top displacement that can be calculated by expressing $\Delta$ from Eq. (9) and (13), and by substituting into them $\Delta l_{12 y, Z 1}$ and $\Delta l_{12 y, Z 2}$ from Eq. (19) and (20), respectively:

$$
\Delta_{y}=\left\{\begin{array}{l}
\frac{h}{x} \cdot \Delta l_{12 y, Z 1} \\
\frac{h}{L \cdot \cos \alpha} \cdot \Delta l_{12 y, Z 2}
\end{array}\right\}=\frac{f_{y} \cdot h}{E} \cdot \frac{1}{\sin \alpha \cdot \cos \alpha}
$$

Therefore, strips yield at the same top horizontal displacement $\Delta_{y}$, given by Eq. (21), regardless of their position in the cell. Even the yield displacement of the variable length strips in Zone 1 does not depend on the position of the strip in the cell. Interesting to note that $\Delta_{y}$ is linearly dependent on the height of the cell $(h)$, but not dependent on $L$.

In conclusion, Eq. (7), (18) and (21) express the load bearing capacity $(V)$, the rigidity $\left(K_{T O T}\right)$ and the yield displacement $\left(\Delta_{y}\right)$ of the wall-cell. The wall-cell, modelled with the strip model, has elastic-plastic behaviour, provided that the strips have elastic-plastic behaviour; and only two of the three equations are independent, while the third can always be expressed from the other two.

\subsection{Evaluation of the Inclination Angle of the Strips ( $\alpha$ )}

As it can be observed in Eq. (7) and (18), in order to calculate the capacity and rigidity of a cell, one should previously determine the inclination of the strips $\alpha$ (Figure 5). Based on FE modelling, corresponding to usual dimensions of the walls, in this paper a proposal is made for the empirical evaluation of $\alpha$.

For the sake of simplicity Elgaaly [2] suggested that the angle should be taken as $\alpha=45^{\circ}$, regardless of the dimensions of the wall. However, it can be observed that the use of $\alpha=45^{\circ}$ in Eq. (7) leads to a maximisation of the expression and to an unsafe over-estimation of the design capacity.

On the other hand, as early as in Wagner's [7] work a formulation was presented for the evaluation of $\alpha$, based on the minimisation of the strain energy accumulated during the deformation. The formula takes into account the strain energy due to the tension-field in the plate and due to the axial force in the frame members. Timler and Kulak [8] amended the formula of Wagner by including the bending effect of the frame members. They argued that the bending for members with plate on both sides (ex. intermediate studs in LGS walls) can be neglected, but for members with plate acting on one side it should be taken into account. This second case applies for marginal studs and tracks in LGS walls. Both proposals neglect the compression and shear stresses in the plate.

If the frame members are considered infinitely rigid, both under axial loading and in bending, the strain energy due to the tension-field action in the plate remains the only factor to be taken into account. In this case, the strain energy is minimum for $\alpha=45^{\circ}$ independently of the dimensions of the plate. 
However, experimental observations and preliminary FEM analyses, using rigid frame members, have shown that this is not the case. In reality $\alpha$ depends on the dimensions of the plate, probably due to the presence of the compression and shear stresses.

A series of FE models have been prepared for the evaluation of $\alpha$, and for the verification of the capacity and the rigidity formulae (Eq. $7 \& 18$ ). The models, developed in ABAQUS 6.5, consisted of a perfectly pinned frame modelled as beams (Linear line type B31) with the thin steel plate modelled as shell (Quadratic quadrilateral type S8R).

The flatness of the plate was locally disturbed close to the midpoint, by a self-balancing pair of small out-of-plane bending moments, before applying lateral loading at the top. Then the cell was subjected to steadily increasing lateral load at the top, and the yield pattern was left to develop without further disturbance. The analysis was performed with displacement control, and the model included both geometrical and material non-linearity.

In the first stage, the $h / L$ ratio ranged from 1.42 to 6.17 (Table 1). The behaviour of the plate material was elastic-plastic with $f_{y}=210 \mathrm{~N} / \mathrm{mm}^{2}\left(E=210000 \mathrm{~N} / \mathrm{mm}^{2}\right)$ and no limitation on the plastic strain. The thickness of the plate was $t=0.6 \mathrm{~mm}$, the plate being continuously connected to the frame. The inclination angles, evaluated using the FE models, are summarized in Table 1.

Table 1. Cases of Cells Calculated with FEM and Analytically

\begin{tabular}{|c|c|c|c|c|c|c|}
\hline Model & $h$ & $L$ & $h / L$ & $\alpha_{F E M}$ & $V(E q .7)$ & $K_{\text {TOT }}(E q .18)$ \\
\hline & $\mathrm{mm}$ & $\mathrm{mm}$ & & deg & $\mathrm{N}$ & $\mathrm{N} / \mathrm{mm}$ \\
\hline $2 \_1$ & 1700 & 600 & 2.83 & 39.0 & 36801 & 10538 \\
\hline $2 \_2$ & 2200 & 600 & 3.67 & 34.9 & 35697 & 7662 \\
\hline $2 \_3$ & 2700 & 600 & 4.50 & 32.3 & 34202 & 5731 \\
\hline $2 \_4$ & 3200 & 600 & 5.33 & 30.3 & 32333 & 4321 \\
\hline $2 \_5$ & 3700 & 600 & 6.17 & 25.0 & 30109 & 3241 \\
\hline 3_1 & 1700 & 900 & 1.89 & 39.8 & 55906 & 16213 \\
\hline $3 \_2$ & 2200 & 900 & 2.44 & 37.8 & 54611 & 11954 \\
\hline $3 \_3$ & 2700 & 900 & 3.00 & 35.6 & 52718 & 9077 \\
\hline 3_4 & 3200 & 900 & 3.56 & 31.1 & 50248 & 6958 \\
\hline 355 & 3700 & 900 & 4.11 & 27.7 & 47227 & 5316 \\
\hline 4_1 & 1700 & 1200 & 1.42 & 42.1 & 75186 & 21992 \\
\hline 4_2 & 2200 & 1200 & 1.83 & 40.3 & 73948 & 16439 \\
\hline $4 \_3$ & 2700 & 1200 & 2.25 & 37.8 & 71900 & 12663 \\
\hline $4 \_4$ & 3200 & 1200 & 2.67 & 34.2 & 69064 & 9858 \\
\hline $4 \_5$ & 3700 & 1200 & 3.08 & 30.6 & 65472 & 7662 \\
\hline
\end{tabular}

In a second stage, further FE models were developed in order to improve the prediction for the angle. Cells with length of $L=600,900,1200,1600 \mathrm{~mm}$; width of $h=1400,1800,2200,2600,3000$, $3400 \mathrm{~mm}$, and plate thicknesses of $t=0.4 ; 0.6 ; 0.8$ and 1.2 have been analysed. The yield stress of $f_{y}=350 \mathrm{~N} / \mathrm{mm}^{2}$ has been used for the steel plate. 
Based on the first set of data the following empirical formulation was proposed by Fülöp [10] for the evaluation of $\alpha$ :

$$
\alpha_{D E G}=45-0.006 \cdot(h-L)
$$

The results of the second set of FE modelling highlighted that the thickness of the sheathing plate also influences the inclination angle. Consequently, an improved form of the equation is proposed, which includes the effect of the plate thickness:

$$
\alpha_{D E G}=45-(0.0035 \cdot t+0.00263) \cdot(h-L)
$$

The reliability of Eq. 22 and 23 has been evaluated using $E R$, the average absolute value calculated from the relative error of the predictions, based on the data from the two stages of the analysis. $E R$ and its standard deviation $\sigma_{E R}$ are presented in Table 2. A comparison plot of the angles given by the proposed expression (Eq. 23) and the angles evaluated using the FEM is shown in Figure 7.

\begin{tabular}{|c|c|c|c|c|}
\hline Analysis stage & $\begin{array}{l}\text { Plate } \\
\text { thickness }(t)\end{array}$ & Formula & $\begin{array}{l}E R \\
(\%)\end{array}$ & $\begin{array}{l}\sigma_{E R} \\
(\%)\end{array}$ \\
\hline \multirow{2}{*}{1} & \multirow{2}{*}{ All } & Eq. 22 & 2.06 & 1.37 \\
\hline & & Eq. 23 & 6.03 & 5.03 \\
\hline \multirow{5}{*}{2} & All & \multirow{5}{*}{ Eq. 23} & 2.66 & 2.62 \\
\hline & $\mathrm{t}=0.4 \mathrm{~mm}$ & & 2.20 & 1.52 \\
\hline & $\mathrm{t}=0.6 \mathrm{~mm}$ & & 1.74 & 7.39 \\
\hline & $\mathrm{t}=0.8 \mathrm{~mm}$ & & 2.54 & 2.70 \\
\hline & $\mathrm{t}=1.2 \mathrm{~mm}$ & & 4.16 & 3.55 \\
\hline $1+2$ & All & Eq. 23 & 3.12 & 3.27 \\
\hline
\end{tabular}

Table 2. Reliability of the Proposed Formula for $\alpha$ (Eq. 22 and 23)

It can be noticed in Table 2 that, the values of the error $E R$ are larger for the thicker plates (ex. $t=1.2 \mathrm{~mm})$. This highlights the fact that, for larger thicknesses, the effect of compression and shear stresses become important, and the behaviour can be less and less accurately described by the tension strip model.

It is also notable that the angles evaluated with the first set of FE models $\left(t=0.6 \mathrm{~mm}, f_{y}=210 \mathrm{~N} / \mathrm{mm}^{2}\right)$ show good fit with Eq. 23 only for some cases (Figure 7). The difference becomes more significant as the $h / L$ ratio increases, as it can be seen also from the larger errors $E R$ and $\sigma_{E R}$ (Table 2). This may point to the yield stress having an effect on $\alpha$. However, in practical applications, the range of the yield stress of the plate is quite narrow and the resulting variation of the angle not significant.

It is important to note again that Eq. 23 is empirical, based on the evaluation of the angle from FEM, so its accuracy may be uncertain. However, it was judged that this accuracy is enough for the evaluation of the angle in practical cases, especially because $\alpha$ in the expressions for strength (Eq. 7) and stiffness (Eq. 18) is used in trigonometrical functions that reduce the variability in the vicinity of $45^{\circ}$. 


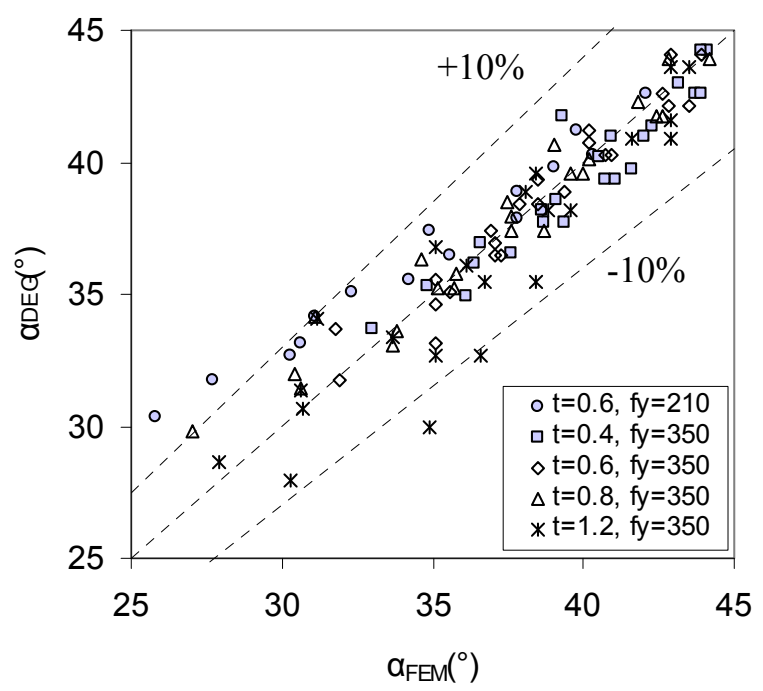

Figure 7. Comparison of the Angle $\alpha$ Values. FEM vs. Eq. (23)

\subsection{Validation of the Strength and Rigidity Formulas}

The previously presented FE models were also used for the checking of the accuracy of the analytical formulas for strength (Eq. 7) and rigidity (Eq. 18). The strength $(V)$ and rigidity $\left(K_{T O T}\right)$ of the cells have been calculated by using Eq. (7) and (18), for the cases corresponding to the first step of the FE study, and have been compared to the characteristic curves obtained by FEM (Table 1). For example, the nonlinear FEM characteristic curves for the cells with $L=1200 \mathrm{~mm}$ are compared in Figure 8 with the equivalent elastic-plastic line, based on the analytical rigidity and capacity from Table 1.

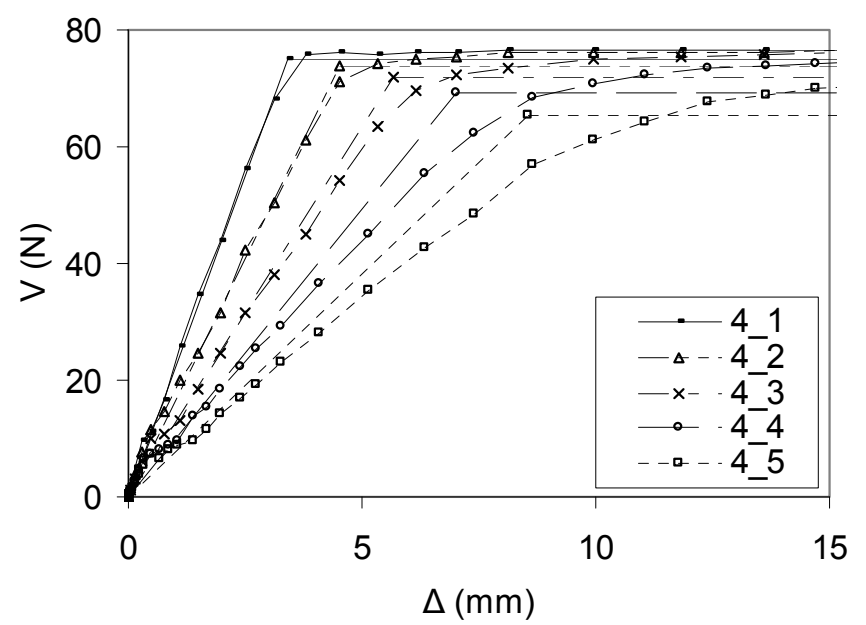

Figure 8. Analytical vs. FEM Curves for Walls with $L=1200 \mathrm{~mm}$

A bump, corresponding to the buckling of the plate, can be observed at the beginning of each characteristic curve obtained by FEM. It can be noticed that the rigidity is higher at the very beginning of the curves; but once the plate buckles the rigidity decreases, the response stabilizes, and the rest of the curve is purely due to the tension-field action. 
According to the analytical formulation (Eq. 21) all strips in the equivalent strip model should yield at the same lateral displacement $\Delta_{y}$. The tendency to have a distinct yield point can also be observed on the characteristic curves obtained by FEM (Figure 8). The effect is more obvious for lower $h / L$ ratios and tends to be attenuated for very high ones.

In some cases the prediction of the rigidity is less accurate. The results suggest that the accuracy of the strip model decreases as the $h / L$ ratio increases, but the difference between the FEM result and Eq. (18) was not more than $20 \%$ for the cases presented in Table 1 . Of course, very large $h / L$ ratios are not feasible, and for practical applications the upper limit of $h / L \approx 5$ is suggested.

The rigidity determined by FEM is always bigger than the one calculated analytically. This is due to the fact that the analytical calculation ignores secondary load transmission by compression or shear stresses in the plate.

Overall, both $V$ and $K_{T O T}$ are well predicted by the analytical formulation, suggesting that the strip model is adequate to describe the behaviour of the thin plate.

\section{CALCULATION METHOD FOR WALLS WITH PLATE CONNECTED TO THE FRAME IN POINTS}

The expressions presented in the previous chapters are valid only as long as the yielding capacity of each individual strips is equal. This is true if the steel plate is connected to the frame continuously. However, if the plate is connected to the frame in points, several failure modes of the plate can develop, like: (1) the yielding of the plate, (2) the failure of the connections on the vertical edge, (3) net-section failure of the plate in the vertical connection line, (4) failure of the connections on the horizontal edge, and (5) net-section failure of the plate in the horizontal connection line. Each of these failure modes, and the behaviour of the components causing them, has to be taken into account in terms of both capacity and rigidity.

\subsection{Evaluation of the Load Bearing Capacity}

The effect of the failure modes can be incorporated in the strength calculation, by assigning, at the strip level, a characteristic resistance to each mode. The smallest of these characteristic resistances will point to the governing failure mode of the strip and will determine its tensile capacity, $d F_{S}$ in Eq (1). The practical way to take into account the failure modes is to operate with stresses instead of forces. In case of each strip, an equivalent yield stress $\left(f_{y, e c h}\right)$ will correspond to each failure mode, and the smallest of these yield stresses will be the basis for the calculation of the strip resistance $\left(d F_{S}=\min \left(f_{y, e c h, 1}, f_{y, e c h, 2} \ldots\right) \cdot t \cdot d x\right)$. Similar procedure was proposed by Elgaaly [2].

All five enumerated failure modes influence the capacity in the case of strips from Zone 1 and 3; but in the case of strips in Zone 2, only the first three modes exist.

The equivalent yield stresses corresponding to each failure mode are:

(i) The yielding of the strip at force $d F_{S}=f_{y} \cdot t \cdot d x$ is the basic case. The yield stress is $f_{y}$.

(ii) The equivalent stress corresponding to the capacity of the vertically placed connectors can be expressed as: 


$$
f_{y, e c h, s}^{V}=\frac{F_{B S}}{S \cdot t} \cdot \frac{1}{\sin \alpha}
$$

Where, the capacity of one connector is $F_{B S}$ and the spacing of the connectors is $S$ (Figure 9).

(a)

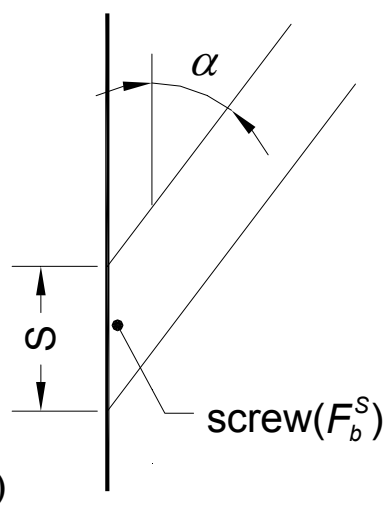

(b)

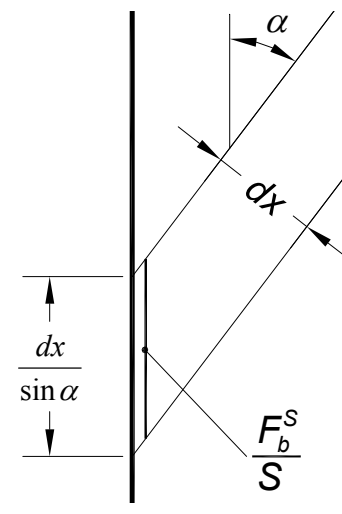

Figure 9. (a) One Screw in the Vertical Row and (b) Characteristics of the Screw Reduced to $d x$

If the connectors are self-tapping screws, the bearing capacity of a screw is $F_{B S}=\alpha_{E C 3} \cdot f_{u} \cdot d \cdot t$, according to prEN-1993-1-3 [11], and Eq. 24 becomes:

$f_{y, e c h, s}^{V}=\frac{\alpha_{E C 3} \cdot f_{u} \cdot d}{S \cdot \sin \alpha}$

It should be noted that only bearing failure of the screws is acceptable, because this failure mode ensures ductile behaviour of the wall. Bearing failure is easily obtained as the thickness of the plate is considerably smaller than that of the profiles of the skeleton. Therefore, the joint is a typical thin-to-thick sheath connection that usually fails by bearing, if the end distances are adequate.

(iii) The equivalent stress for net-section failure in the vertical connection line, can be calculated, using the definition of net-section area given in prEN-1993-1-1 [12], when both normal and tangential stresses act on the net-section surface:

$$
A_{\text {net }}=A_{\text {gross }}-t \cdot\left(n \cdot d-\sum \frac{s^{2}}{4 \cdot p}\right)
$$

The net-section area expression can be adapted for the oblique strips having a width of $S$ (Figure 10):

$$
A_{n e t}=t \cdot(S-d)+\frac{t \cdot S}{4} \cdot \frac{\cos ^{2} \alpha}{\sin \alpha}
$$

Therefore, based on net-section failure, and reduced to $d x$ width, the capacity of the $\operatorname{strip}\left(F^{V}{ }_{n e t}\right)$ is:

$$
F_{n e t}^{V}=f_{u} \cdot A_{n e t, d x}^{V}=f_{u} \cdot t \cdot d x \cdot\left[\frac{1-d / S}{\sin \alpha}+\frac{t}{4} \cdot \frac{1}{\tan ^{2} \alpha}\right]
$$




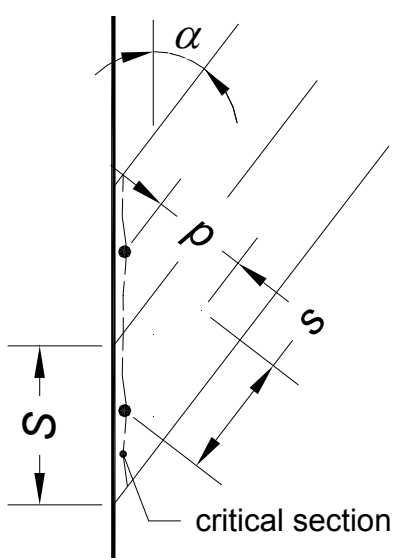

Figure 10. Net-section Failure of the Vertical Screw Line

And the corresponding equivalent yield stress reads:

$f_{y, e c h, n e t}^{V}=f_{u} \cdot\left[\frac{1-d / S}{\sin \alpha}+\frac{t}{4} \cdot \frac{1}{\tan ^{2} \alpha}\right]$

(iv) The equivalent yield stress corresponding to the capacity of horizontally placed connectors is:

$f_{y, e c h, s}^{H}=\frac{F_{B S}}{S \cdot t} \cdot \frac{1}{\cos \alpha}$

Or, based on the bearing capacity of the self-tapping screws [11]:

$f_{y, e c h, s}^{H}=\frac{\alpha_{E C 3} \cdot f_{u} \cdot d}{S \cdot \cos \alpha}$

(v) The equivalent yield stress for net-section failure of the horizontal connector line reads:

$f_{y, e c h, n e t}^{H}=f_{u} \cdot\left[\frac{1-d / S}{\cos \alpha}+\frac{t}{4} \cdot \tan ^{2} \alpha\right]$

The equivalent yield-stresses for a strip in Zone 1 or $3\left(f_{y, 1,3}\right)$ and Zone $2\left(f_{y, 2}\right)$ can be expressed using Eq. (24) or (25), (29), (30) or (31) and (32), as:

$$
\begin{aligned}
& f_{y, 1,3}=\min \left(f_{y}, f_{y, e c h, s}^{V}, f_{y, \text { ech }, \text { net }}^{V}, f_{y, e c h, s}^{H}, f_{y, e c h, \text { net }}^{H}\right) \\
& f_{y, 2}=\min \left(f_{y}, f_{y, e c h, s}^{V}, f_{y, \text { ech,net }}^{V}\right)
\end{aligned}
$$

The capacity of a wall-cell with steel plate, connected on every edge by using a uniform scheme of connectors, can be written in similar form as in Eq. (7), but using the equivalent yield stresses derived above: 


$$
\begin{aligned}
V & =2 \cdot \int_{x=0}^{L \cdot \cos \alpha} \frac{d F_{S, 1,3} \cdot x}{h}+\int_{x=L \cdot \cos \alpha}^{h \cdot \sin \alpha} \frac{d F_{S, 2} \cdot L \cdot \cos \alpha}{h}= \\
& =\frac{t \cdot L}{h} \cdot\left[f_{y, 1,3} \cdot L \cdot \cos ^{2} \alpha+f_{y, 2} \cdot \cos \alpha \cdot(h \cdot \sin \alpha-L \cdot \cos \alpha)\right]
\end{aligned}
$$

If the connector distance $S$ is not constant on the perimeter of the steel plate, the already defined three zones can be further divided in sub-zones that are homogeneous from the point of view of equivalent yield stress. The capacity expression, for one cell, can be derived by summing up the individual contributions on intervals corresponding to these sub-zones, similarly to Eq. (6).

\subsection{Priority of the Failure Modes}

In the expression of the equivalent yield stresses (Eq. 24, 29, 30, 32), the angle $\alpha$ should be evaluated using Eq. 23, valid for the dimensions $L \approx 600 \ldots 1600 \mathrm{~mm}, h \approx 1400 \ldots 3700 \mathrm{~mm}$, $t \approx 0.4 \ldots 1.2 \mathrm{~mm}$. It can be observed that, the angle is in the range of $\alpha \approx 25 \ldots 65^{\circ}$, for the walls in the above range of dimensions, corresponding to the practical configurations. This property of $\alpha$ can be used to limit the value of the trigonometric functions in the expressions of the yield stresses. Also, it can be shown that the bearing failure of the screws is the most probable failure mode, if self-tapping screws are used as connectors between the plate and the frame of the wall.

The five possible failure modes, discussed in the calculation procedure, resulted in five equivalent stress values: $f_{y}$ and the ones from Eq. (24), (29), (30), and (32).

In order to have bearing failure of the connections before yielding of the plate, the following condition of the equivalent yield stresses should be fulfilled, based on Eq. (24) and (30):

$$
\left.\begin{array}{l}
f_{y, \text { ech }, \mathrm{S}}^{V}=\frac{F_{B S}}{S \cdot t} \cdot \frac{1}{\sin \alpha} \\
f_{y, \text { ech }, \mathrm{S}}^{H}=\frac{F_{B S}}{S \cdot t} \cdot \frac{1}{\cos \alpha}
\end{array}\right\}<f_{y} \Rightarrow F_{B S}<\left\{\begin{array}{l}
S \cdot t \cdot f_{y} \cdot \sin \alpha \\
S \cdot t \cdot f_{y} \cdot \cos \alpha
\end{array}\right.
$$

The limitation $25^{\circ}<\alpha<65^{\circ}$ leads to $\{\sin \alpha, \cos \alpha\}>0.422$. If the connectors are self-tapping screws, we have $F_{B S}=\alpha_{E C 3} \cdot d \cdot t \cdot f_{u}$, where $\max \left(\alpha_{E C 3}\right)=2.1$ and $f_{u} / f_{y} \approx 1.2[11]$; and the condition from Eq. (36) becomes:

$$
\alpha_{E C 3} \cdot d \cdot t \cdot f_{u}<0.422 \cdot S \cdot t \cdot f_{y} \Rightarrow S>5.97 \cdot d
$$

For the usual self-tapping screw diameters $(\mathrm{d}=4.2,4.8,5.5 \mathrm{~mm})$ this leads to $S \approx 33 \mathrm{~mm}$, and the screw spacing will be probably larger in practical applications.

Net-section failure can take place when connections are placed closely. In order to avoid it, a minimum $S$ can be calculated by comparing the equivalent yield stresses from Eq. (24), (29), (30) and (32):

$$
\left\{\begin{array} { l } 
{ f _ { y , \text { ech } , S } ^ { V } < f _ { y , \text { ech,net } } ^ { V } } \\
{ f _ { y , \text { ech } , S } ^ { H } < f _ { y , \text { ech,net } } ^ { H } }
\end{array} \Rightarrow \left\{\begin{array}{l}
F_{B S}<S \cdot t \cdot f_{u} \cdot\left[1-\frac{d}{S}+\frac{t}{4} \cdot \frac{\cos ^{2} \alpha}{\sin \alpha}\right] \\
F_{B S}<S \cdot t \cdot f_{u} \cdot\left[1-\frac{d}{S}+\frac{t}{4} \cdot \frac{\sin ^{2} \alpha}{\cos \alpha}\right]
\end{array}\right.\right.
$$


The trigonometric functions can be minimized based on the limits for the angle $\left(25^{\circ}<\alpha<65^{\circ}\right)$, $\min \left\{\frac{\sin ^{2} \alpha}{\cos \alpha}, \frac{\cos ^{2} \alpha}{\sin \alpha}\right\}=0.197 \approx 0.2$; and the condition to avoid net-section failure rewritten as:

$F_{B S}<S \cdot t \cdot f_{u} \cdot\left[1-\frac{d}{S}+0.05 \cdot t\right]$

If the connectors are self-tapping screws with bearing capacity $F_{B S}=\alpha_{E C 3} \cdot d \cdot t \cdot f_{u}$, with $\max \left(\alpha_{E C 3}\right)=2.1 \quad[11]$, the condition becomes:

$S>\frac{3.1 \cdot d}{1+0.05 \cdot t}$

Hence, in the extreme case of $t=0, S>3.1 \cdot d$ is the condition for net-section failure to be avoided. Therefore, for usual wall dimensions, and when self-tapping screws are used as connectors between the steel plate and the frame of the wall, the bearing of the screws should be the main failure mode, based on the simplified formulae from prEN-1993-1-3 [11], and if $S>6 \cdot d$. Such screw spacing is the usual case in practical applications.

\subsection{Evaluation of the Rigidity}

The influence of the connections can be included in the rigidity formulation, similarly as in the case of capacity (Eq. 35). At the level of one strip, the connection plays a role due to their rigidity, transforming the strip in a series of three springs: (1) a spring representing the effect of the connection with the vertical edge, (2) one corresponding to the steel strip itself, and (3) one representing the connections with the horizontal edge (Figure 11). The rigidity of the spring system can be expressed based on these three components for strips in Zone 1, 3 and strips in Zone 2 as:

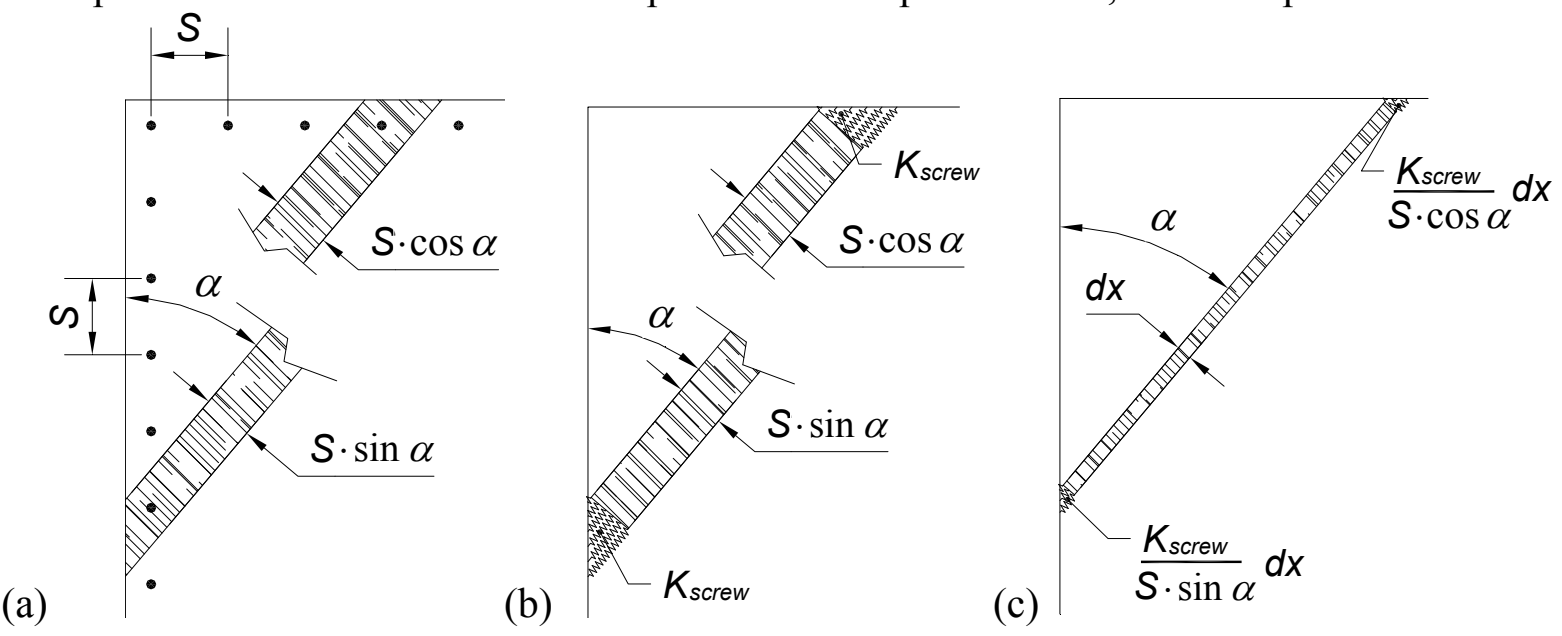

Figure 11. Rigidity of a Strip: (a) Real Arrangement, (b) Projected and (c) Reduced to $d x$

$\frac{1}{k_{s, Z 1}}=\frac{1}{k_{V}}+\frac{1}{k_{s t}}+\frac{1}{k_{H}}$ and $\frac{1}{k_{s, Z 2}}=\frac{1}{2 \cdot k_{V}}+\frac{1}{k_{s t}}$

Where $k_{s, Z 1}$ and $k_{s, Z 2}$ are the rigidity of a strip as in Eq. (11) and (14), and the components corresponding to the screws can be expressed as follows (Figure 11.c.): 
$k_{V}=\frac{k_{\text {screw }}}{S \cdot \sin \alpha} \cdot d x$ and $k_{H}=\frac{k_{\text {screw }}}{S \cdot \cos \alpha} \cdot d x$

By substituting the expressions above in the Eq. (41), the rigidities of strips $k_{s, Z 1}$ and $k_{s, Z 2}$ become:

$$
\begin{aligned}
& k_{s, Z 1}=\frac{1}{\frac{S \cdot(\sin \alpha+\cos \alpha)}{k_{\text {screw }}}+\frac{x}{t \cdot E \sin \alpha \cdot \cos \alpha}} \cdot d x \\
& k_{s, Z 2}=\frac{1}{\frac{2 \cdot S \cdot \sin \alpha}{k_{\text {screw }}}+\frac{L}{t \cdot E \cdot \sin \alpha}} \cdot d x
\end{aligned}
$$

If the expressions from Eq. (43) and (44) are introduced in the corresponding Eq. (15) for Zone 1 and (17) for Zone 2, the rigidity contribution of all strips in Zone 1 or $3\left(K^{\text {Zonel }}\right)$ and in Zone 2 $\left(K^{\text {Zone2 }}\right)$ become:

$$
\begin{aligned}
K^{\text {Zone } 1} & =K^{\text {Zone } 3}=\int_{0}^{L \cdot \cos \alpha} \frac{1}{C 1+C 2 \cdot x} \cdot \frac{x^{2}}{h^{2}} \cdot d x= \\
& =-\frac{C 1}{C 2^{2}} \cdot \frac{L \cdot \cos \alpha}{h^{2}}+\frac{1}{2 \cdot C 2} \cdot \frac{L^{2} \cdot \cos ^{2} \alpha}{h^{2}}+\frac{C 1^{2}}{C 2^{3} \cdot h^{2}} \cdot[\ln (C 1+C 2 \cdot L \cdot \cos \alpha)-\ln (C 1)]
\end{aligned}
$$

And,

$$
K^{\text {Zone } 2}=\int_{h \cdot \cos \alpha}^{L \cdot \sin \alpha} \frac{L^{2} \cdot \cos ^{2} \alpha}{h^{2}} \cdot C 3 \cdot d x=C 3 \cdot \frac{L^{2} \cdot \cos ^{2} \alpha}{h^{2}} \cdot(h \cdot \sin \alpha-L \cdot \cos \alpha)
$$

Where:

$$
C 1=\frac{S \cdot(\sin \alpha+\cos \alpha)}{k_{\text {screw }}} ; C 2=\frac{1}{t \cdot E \cdot \sin \alpha \cdot \cos \alpha} \text { and } C 3=\frac{1}{\frac{2 \cdot S \cdot \sin \alpha}{k_{\text {screw }}}+\frac{L}{t \cdot E \cdot \sin \alpha}}
$$

It can be observed that Eq. (45) and (46) are equivalent to Eq. (15) and (17), and they show the rigidity contributions of strips in Zone 1, 3 and Zone 2, but now include also the effect of the connections. To calculate the total rigidity of the cell, the effects of the strips in Zone 1, Zone 2 and Zone 3 have to be added:

$$
K_{\text {TOT }}=2 \cdot K^{\text {Zone1 }}+K^{\text {Zone2 }}
$$

These expressions are too complex and have limited applicability. Moreover, the elongation of the strips in Zones 1 and 3 (Eq. 43) is not any more linearly dependent on $x$, as in the case of continuous connections (Eq. 9). For this reason, the strips in Zone 1 and 3 do not yield simultaneously as in the case of continuously connected plates. The expression for $V$ (Eq. 35) is valid when all strips are yielded, and the one for $K_{\text {ТОT }}$ (Eq. 47) is accurate as long as the rigidity of the connections is high, as compared to that of the thin plate. 


\section{EXPERIMENTAL AND FEM VALIDATION}

In order to check the validity of the method, proposed for walls with steel plates connected to the frame in points, a simple configuration was tested and modelled by FE (Figure 12). The configuration is characterized by: $h=2700 \mathrm{~mm}, L=1200 \mathrm{~mm}, t=0.715 \mathrm{~mm}, f_{y}=420 \mathrm{~N} / \mathrm{mm}^{2}$, $f_{u}=510 \mathrm{~N} / \mathrm{mm}^{2}, S=100 \mathrm{~mm}, d=4.8 \mathrm{~mm}$ and $F_{B S}=4.14 \mathrm{kN}[13]$.

a)

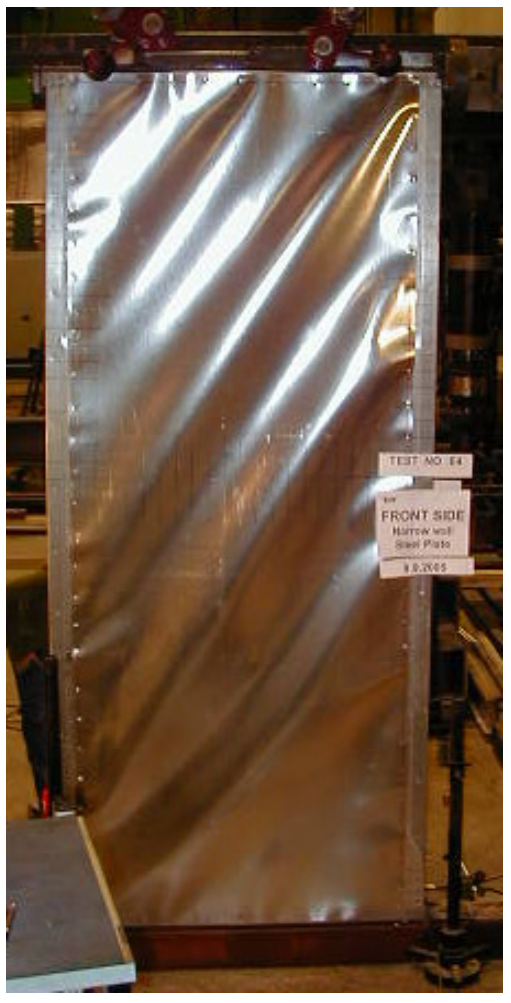

b)

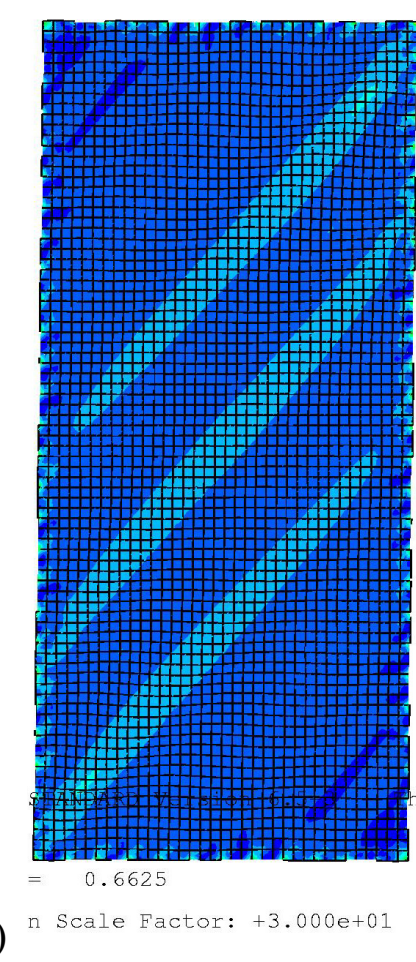

Figure 12. Plate Deformation: (a) Experiment and (b) FEM

The main components defining the capacity of the wall are the screws between the plate and the frame. The capacity of these connections has been determined by lap-joint tests. The test specimens were single screw lap-joints in compliance with ECCS-21 [14], made of the same basic materials as the panel, and using the same screws. Therefore, all material properties for the lap-joints were identical to the ones used in the panel test.

The experimental force displacement curves, for the 5 lap-joint tests, are presented with dashed lines in Figure 13, together with the design resistance prediction of ENV-1993-1-3 [15] and prEN-1-3 [11]. The design resistances were calculated without safety factors, and by using measured material properties and dimensions. Interesting to note, that the resistances, predicted by the two versions of the code, significantly differ: $F_{b, R d}=2162 \mathrm{~N}$ [11] and $F_{b, R d}=3676 \mathrm{~N} \mathrm{[15].}$ 


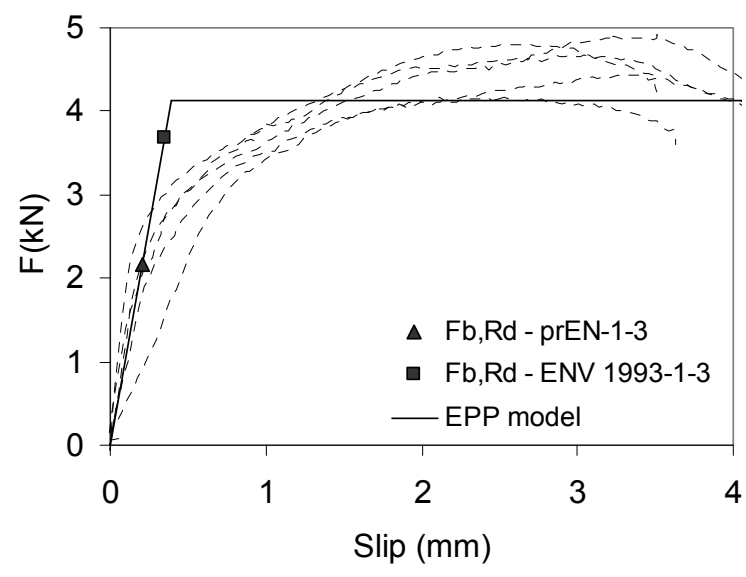

Figure 13. Experimental Curves for Lap-joints

Based on the tests, the rigidity of the connection $\left(k_{\text {screw }}\right)$ was calculated as secant rigidity up to the force of $0.4 \cdot F_{\max }$, and the yield force $\left(F_{y}\right)$ was defined at $0.9 \cdot F_{\max }$. The average values of these characteristics are: $k_{\text {screw }}=10.63 \mathrm{kN} / \mathrm{mm}, F_{\max }=4.59 \mathrm{kN}$ and $F_{y}=4.14 \mathrm{kN}$. The resulting equivalent elastic-plastic curve is also presented in Figure 13.

The load bearing capacity, and rigidity of the wall, have been calculated, by the proposed analytical procedure (Eq. 35, 47), and by FEM, using for the screws: (i) elastic-plastic model with $F_{B S}=F_{y}=4.14 \mathrm{kN}$ (FEM-EPP) or (ii) full non-linear model based on the lap-joint test (FEM-Non). The results of the modelling are compared to the ones obtained from the full scale wall test, in Table 3 and Figure 14.

Table 3. Properties of the Wall in Figure 12

\begin{tabular}{|c|c|c|c|c|c|}
\hline \multicolumn{2}{|c|}{ Analytical } & \multicolumn{2}{|c|}{ FEM-EPP } & \multicolumn{2}{|c|}{ Experimental } \\
\hline $\begin{array}{l}V \\
(\mathrm{~N})\end{array}$ & $\begin{array}{l}K_{T O T} \\
(\mathrm{~N} / \mathrm{mm})\end{array}$ & $\begin{array}{l}V_{F E M} \\
(\mathrm{~N})\end{array}$ & $\begin{array}{l}K_{F E M} \\
(\mathrm{~N} / \mathrm{mm})\end{array}$ & $\begin{array}{l}V_{E X P} \\
(\mathrm{~N})\end{array}$ & $\begin{array}{l}K_{E X P} \\
(\mathrm{~N} / \mathrm{mm})\end{array}$ \\
\hline 33469 & 6869 & 32857 & 6488 & 34183 & 1329 \\
\hline
\end{tabular}

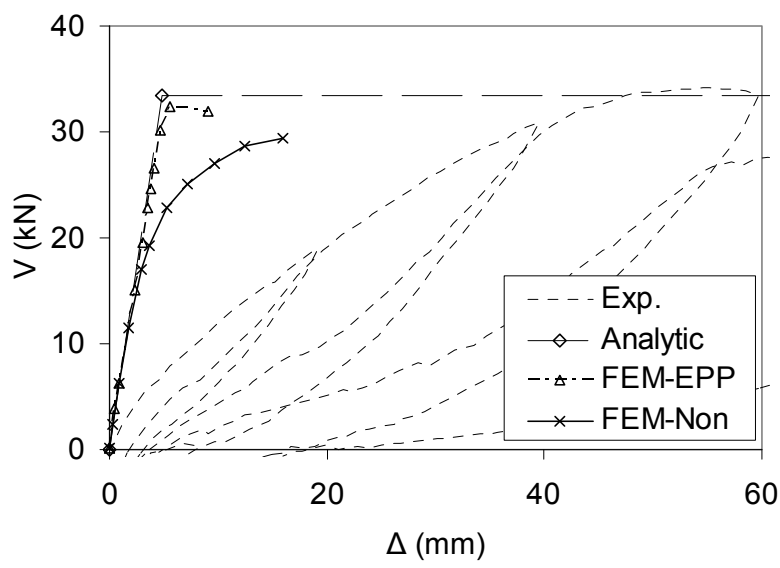

Figure 14. Predicted Behaviour of the Wall 
The strength $(V)$ formulation is validated by both the FEM and experimental results (Figure 14), but in order to be accurate, the calculation method of the rigidity should take into account additional sources of flexibility (e.g. corner flexibility). The rigidity obtained analytically $\left(K_{T O T}\right)$ still compares well with the FEM results, which means that the analytical model correctly predicts the rigidity, at least in regard to the phenomena incorporated in the model.

\section{CONCLUSIONS}

An analytical calculation method has been developed for the evaluation of the capacity and the rigidity of LGS wall panels sheathed with thin steel plates. The method is based on the assumptions that: (i) the elements of the skeleton are rigid but hinged at the ends, and (ii) the steel plate transmits the load only by tension-field action. The oblique tension stress pattern, developing within the steel plate, is replaced for the calculation by strips that are subject only to tension.

The rigidity $\left(K_{T O T}\right)$ and the capacity $(V)$, of the wall panels, are predicted with good accuracy in the case of a continuous connection of the steel plate to the frame. For this case, the analytical calculations have been compared to FEM results.

An empirical formula is proposed for the evaluation of the angle by which the yield pattern develops $(\alpha)$. The formula is based on extensive FEM analysis, and is valid for the most usual wall dimensions in practical applications.

The effects of the connection between the frame and the steel plate have been incorporated into the analytical model, proposing formulas for the calculation of the capacity (Eq. 35) and rigidity (Eq. 47) of such walls. The strength formula was found to be sufficiently accurate, when compared to FE modelling and test results.

When self-tapping screws are used to connect the steel plate to the frame, it was shown that the failure mode of the wall will be governed by the bearing of the screws. This conclusion is based on design expressions from prEN 1993-1-3 [11], and applies for usual geometric configurations. This observation can be used for further simplification of the procedure.

\section{ACKNOWLEDGEMENT}

The material contained in this paper is based on the work supported by the European Community's Sixth Framework Program, Marie Curie project MEIF- CT-2005-009448. This support is gratefully acknowledged. All opinions, findings, conclusions or recommendations expressed in this material are those of the writers. The European Community is not liable for any use of the information contained in this paper. 


\section{REFFERENCES}

[1] Davies, J.M., "The Use of Cassette Sections in Prefabricated Low Rise Construction. In D. Dubina, I. Vayas \& V. Ungureanu (eds.)", New Technologies and Structures in Civil Engineering, Case Studies on Remarkable Constructions, 1999, Timisoara.

[2] Elgaaly, M., "Thin Steel Plate Shear Walls Behavior and Analysis", Thin Walled Structures, 1998, Vol. 32, pp. 151-180.

[3] Berman, J. \& Bruneau, M., "Plastic Analysis and Design of Steel Plate Shear Walls", Journal of Structural Engineering, 2003, Vol. 129, No. 11, pp. 1448-1456.

[4] Nakashima, M. et al., "Energy Dissipation Behavior of Shear Panels Made of Low Yield Steel”, Earthquake Engineering and Structural Dynamics, 1994, Vol. 23, pp. 1299-1313.

[5] De Matteis, G., Mazzolani, F.M., Panico, S., "Pure Aluminium Shear Panels as Passive Control System for Seismic Protection of Steel Moment Resisting Frames", Proc. of the 4th International Conference STESSA 2003, Mazzolani F.M. Editor, A.A. Naples, 2003, 9-12 June, Rotterdam: Balkema.

[6] Astaneh-Asl, A., "Seismic Behavior and Design of Steel Shear Walls", Structural Steel Educational Council, 2001, Moraga, California.

[7] Wagner, H., "Flat Sheet Metal Girder with Very Thin Metal Web. Part 1. General Theories and Assumptions", Technical Memorandum No. 2662, 1931, Washington DC: NACA.

[8] Timler, P.A. \& Kulak G.L., "Experimental Study of Steel Plate Shear Walls, Structural Engineering Report No. 114, 1983, Department of Civil Engineering, University of Alberta, Edmonton Alberta.

[9] Kuhn, P., "Stresses in aircraft structures", New York: McGraw-Hill, 1955.

[10] Fulop, L.A, Hakola, I., "Design of Light-gauge Steel Shear Walls Sheathed with Thin Steel Plates", Proceedings of the International Conference in Metal Structures "Steel - A New and Traditional Material for Buildings", 20-22 IX 2006, Poiana Brasov, Romania, ISBN 0415408172.

[11] prEN-1-3, “General Rules. Supplementary Rules for Cold-formed Members and Sheeting”, Brussels, 2004.

[12] prEN 1993-1-1, "Design of Steel Structures - Part 1-1: General Rules and Rules for Buildings", Brussels, 2003.

[13] E0012, "Seismic Tests of Shear Walls. Part 2. Report to ECSC, Document PR377/WP3/E0012. Version 1", Helsinki: VTT- Building and Transport, 2005.

[14] ECCS-21, "Recommendations for Steel Construction: The Design and Testing of Connections in Steel Sheeting and Section", Brussels: ECCS Committee TC7. WG 7.2, 1983.

[15] ENV 1993-1-3, "General Rules, Supplementary Rules for Cold-formed Members and Sheeting, Brussels, 1996. 


\section{NOTATIONS}

$A_{\text {net }}$

Agross

$d$

$d A$

$d F_{S}$

$d F_{S, 1,3}$

$d F_{S, 2}$

$d k_{t}^{Z 1}$

$d k_{t}^{Z 2}$

$d x$

E

ER

$f_{H, e c h, s}^{H}$

$f^{H}{ }_{y, e c h, n e t}$

$f_{u}$
$f_{y, \text { ech,s }}^{V}$
$f_{y, \text { ech,net }}^{V^{\prime}}$

$f_{y}$

$f_{y, 1,3}$

$f_{y, 2}$

$f_{y, e c h}$

$F_{B S}$

$F^{V}{ }_{n e t}$

$h$

$k_{H}$

$k_{s, Z 1}$

$k_{s, Z 2}$

$k_{\text {screw }}$

$k_{s t}$

$k_{V}$

$K_{\text {TOT }}$

$K^{\text {Zone1 }}$

$K^{\text {Zone2 }}$

$K^{\text {Zone3 }}$

$l_{12, Z 1}$

$l_{12, Z 2}$

$L$

$n$

$p$

$S$

$S$

$t$

V

$V_{y}$

$V_{i}$

$V_{i}^{\text {Zone } 1}$ net-section in a connection according to prEN-1993-1-1

gross cross section

diameter of bolt or screw

cross section area of one calculation strip

tensile capacity of a calculation strip

equivalent capacity of a strip in Zone 1 and Zone3 $\left(d F_{S, 1,3}=d x \cdot t \cdot f_{y, 1,3}\right)$

equivalent capacity of a strip in Zone $2\left(d F_{S, 2}=d x \cdot t \cdot f_{y, 2}\right)$

contribution of the current strip in Zone1 to the horizontal rigidity of the cell

contribution of the current strip in Zone 2 to the horizontal rigidity of the cell

differential width of the calculation strip

elastic modulus (of steel)

average of the absolute values of the relative error for the prediction of $\alpha$

equivalent yield stress corresponding to the failure of the screws on a horizontal edge

equivalent yield stress corresponding to the net-section failure of a horizontal connection line

ultimate strength

equivalent yield stress corresponding to failure of the screws on a vertical edge

equivalent yield stress corresponding to net-section failure of a vertical connection

line

yield stress of the flat steel plate

equivalent yield stress of strips in Zone 1 or Zone3

equivalent yield stress of strips in Zone 2

equivalent yield stress of a strip

bearing failure of one screw

capacity of a strip corresponding to the net-section failure of the vertical connection line

height of the wall

equivalent distributed rigidity from connections on the horizontal edge

axial rigidity of the current strip in Zone1

axial rigidity of the current strip in Zone2

rigidity of one connection

tension rigidity of the strip

equivalent distributed rigidity from connections on the vertical edge

total shear rigidity of one cell

shear rigidity of the wall due to all strips in Zone1

shear rigidity of the wall due to all strips in Zone2

shear rigidity of the wall due to all strips in Zone3

length of the current strip in Zone1

length of the current strip in Zone2

length of a sheathing cell

number of holes in any diagonal or zig-zag line progressively across the section

distance between bolts perpendicular on the loading direction

distance between bolts parallel to the loading direction

distance between screws

thickness of the flat steel plate

total shear capacity of one cell

shear yield capacity of the wall panel

contribution of one strip to the shear capacity of the cell

contribution of all strips in Zone1 to the shear capacity of the cell 


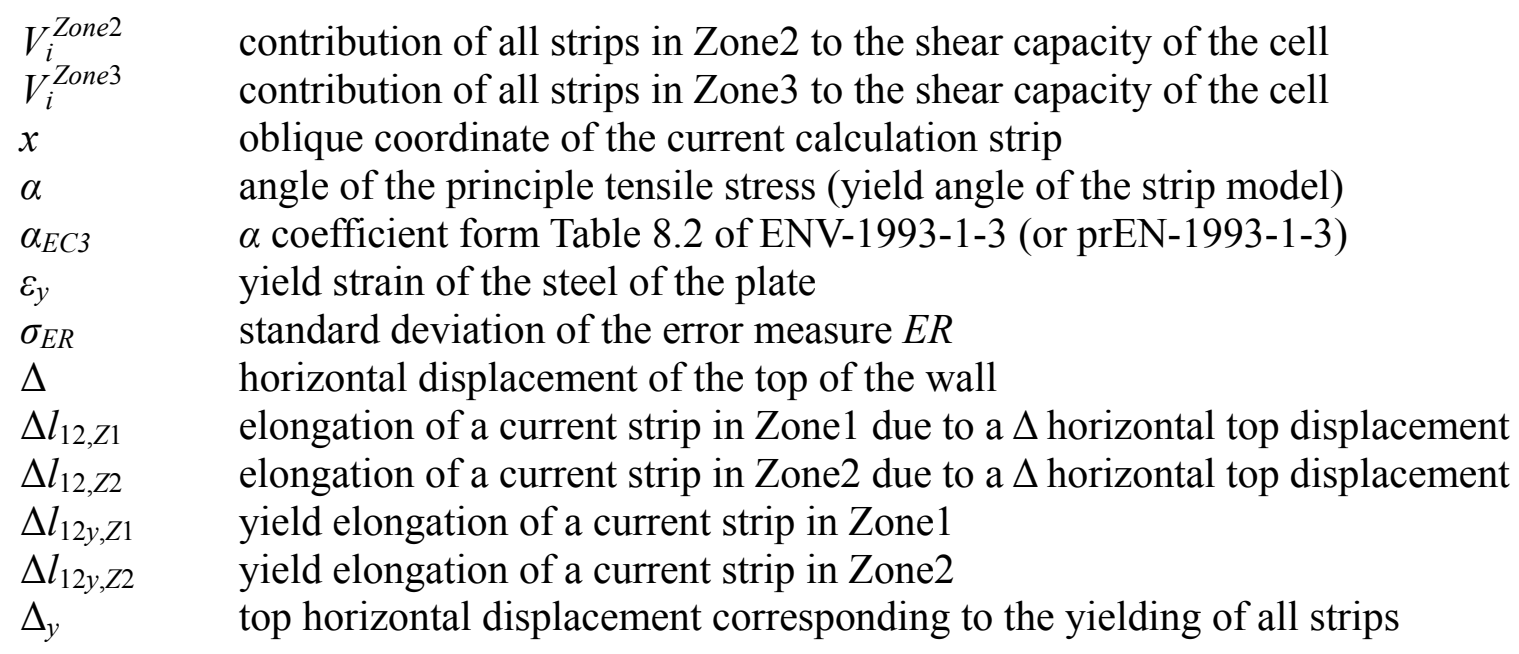

